Article

\title{
Comparison of Relief Shading Techniques Applied to Landforms
}

\author{
Marianna Farmakis-Serebryakova *(D) and Lorenz Hurni 1 \\ Institute of Cartography and Geoinformation, ETH Zurich, 8093 Zurich, Switzerland; lhurni@ethz.ch \\ * Correspondence: mserebry@ethz.ch
}

Received: 6 March 2020; Accepted: 16 April 2020; Published: 18 April 2020

\begin{abstract}
As relief influences disposition of all the other objects displayed on maps, terrain representation plays one of the key roles in the map creation process. Originally a manual technique, relief shading creates the three-dimensional effect and allows the user to read the terrain in an intuitive way. With the advent of digital elevation models (DEMs) analytical relief shading came into a wider use, since it is faster, requires less effort, and delivers reproducible results. In contrast to manual relief shading, however, it often lacks clarity when representing heterogeneous landscapes with diverse landforms. The aim of this work is to evaluate analytical hillshading methods against a set of landforms within an online survey. The responses revealed that the clear sky model performs best applied to most of the landforms included in the survey, in particular all the mountain and valley types. Cluster shading proved to work well for the mountainous and hilly areas but less so in the depiction of valleys. Texture shading and the multidirectional, oblique-weighted (MDOW) method deliver too much detail for most of the landforms presented. Glaciers were depicted in the best way using the aspect tool. For alluvial fans, the standard relief shading with custom lighting direction proved to work best compared to the other methods.
\end{abstract}

Keywords: manual relief shading; analytical relief shading; landforms; user survey

\section{Introduction}

To achieve a proper visual look and easy interpretation of maps with manual relief shading, a cartographer is required to skilfully interpret the terrain and to represent it in an artistic way. As a consequence, results may be subjective and visually greatly vary one from another. Although the last manual touch is nearly always present in relief shading production, creating shaded reliefs manually, especially at small scales, is time consuming and takes much effort to do so on a regular basis. For that reason, shaded relief is nowadays generated mostly automatically, sometimes with further optional enhancements in Photoshop [1] or also by rendering using e.g., Blender software combined with Photoshop filters [2], and the goal of cartographers is to transfer manual techniques, which are often superior, into the automated form.

With this aim in mind, the authors set up an online survey in an attempt to evaluate the perceived effectiveness of a selection of analytical relief shading methods, which is the respondents' satisfaction and graphical attractiveness of shaded relief images. In contrast to effectiveness or efficiency of those methods, the graphical attractiveness deals with subjectivity, and thus it addresses subjective as opposed to objective usability.

Prior research mainly focused on lighting, as it is a key to enhancing a visual quality of relief. One of the essential features of manual relief shading is continuous change of light direction throughout the terrain, and as a result, highlighting every landform optimally according to its orientation. Zakšek et al. [3] emphasize that the main two challenges of analytical hillshading are (1) adequate representation of oblong elements stretching parallel to the light direction, and (2) identifying features 
within cast shadow areas. The present work addresses these issues, and aims at distinguishing the large relief forms in relief shadings.

Starting at the end of the 19th century, the methods to describe spatial surfaces mathematically led to the application of Lambert's Cosine Law by Wiechel [4] to calculate the illumination of a light source on a surface. The Lambertian model was later used by Yoëli [5-7] to enable more continuous and natural shading, which in turn led to automation of relief shading generation and experiments with local adjustments of light direction [8-10].

Furthermore, Brassel [11,12] designed an approach that incorporated the principles of the Swiss style relief shading [13] and attempted to imitate the whole chain of processes to calculate shaded relief by applying both contrast corrections and adjustments of the light direction. A later approach developed into the Shadow software by Jenny [14] allowed for calculation of grey values of an image by applying aspect-based shading for steep regions, diffuse reflection for low areas and grey tones for flat areas. Within a limited area, the user could interactively perform local adaptation of light direction, vertical exaggeration, brightness and tonal changes. Although these adjustments were manual and dependent on the user's decision, they helped to enhance the visual impression of shaded relief.

In the last two decades, more attempts were made to achieve the effects described above. For instance, another way to change the illumination so that it is adapted to the terrain is topographic openness [15], which is an angular measure based on the terrain line of sight and conveying the extent of enclosure of a location. Developed later by Kennelly and Stewart, an enhanced illumination model employed uniform diffuse illumination, where light reflects off a surface and scatters at many angles, to accentuate relative heights of terrain elements [16]. To retrieve more details from deeply shadowed areas and to accentuate the slopes oriented parallel to the standard light direction, diffuse illumination may be used instead of a direct one, which is particularly useful when it comes to small scale features on high-resolution digital elevation models (DEMs) [3]. Further research led to more advanced light setting called sky models [17], which provide many discrete point light sources and were initially widely applied in architectural design over the last century. Topographic details can also be enhanced by changing the azimuth and elevation angle, with generating a grid of multidirectional visibility indices [18], or by combining hill shading with terrain curvature [19]. Depth and shape of the relief forms can be exposed with the help of relief shearing [20,21]. Lastly, a diffusion curve algorithm was introduced by Marston and Jenny [22]; it stems from light direction adjustments based on the orientation of ridges and valleys.

The need for emphasizing features laying parallel to the single-source illumination and for revealing features hidden in the dark, shadowed areas gave an impulse to introducing more than just one light point source but several emanating from different directions. With the help of a geographic information system (GIS), one such method met its implementation in the multidirectional, oblique-weighted (MDOW) relief shading by Mark [23]. As an input, a generalised aspect map was used, and an output is weighted with regard to an image cell's aspect. Today it can be quickly tested by any user since it is embedded in the ArcGIS Terrain Tools [24]. To imitate continuous change of light direction (azimuth) and angle (zenith), which makes manually shaded reliefs easily readable and expressive, Veronesi and Hurni [25] suggested an algorithm based on the clustering aspect in order to change lighting across the terrain. It is implemented as an ArcGIS toolbox and also embedded in the ArcGIS Terrain Tools. A principle of multiple light sources was likewise incorporated by Veronesi and Hurni [26] in another GIS tool, which provides the illumination from two different angles and is able to correct the tone with regard to elevation or slope. Built as an ArcGIS toolbox, it also ensures consistent, reproducible results in visually more appealing shaded reliefs.

Another important element of three-dimensional shading formation is the aerial perspective effect, which means contrast reduction subject to the distance from the viewpoint. Besides increasing three-dimensionality, it also interconnects adjacent generalised landforms and lets the user see the relief convex, since they might look concave when lit obliquely [27]. Technically, atmospheric corrections can be implemented in the currently existing GIS software. For instance, the built-in ArcGIS Hillshade 
function implicates calculation of illumination values for each cell in relation to neighbouring cells with further smoothing. But without considering local light changes and treating a cell as a part of a major landform, the quality of the output image is far from imitating the manual relief shading, leaving room for the design of more efficient tools.

Despite the vast variety of existing techniques nowadays, it would be valuable to have one multipurpose method that would allow for choosing an appropriate illumination model and adjust the amount of light sources or directions in every single landscape setting. For this purpose, this survey is designed to find out which analytical relief shading methods perform better with respect to specific landforms and terrain type.

\section{Survey Design}

To prove whether the selection of landforms is eligible and methods applied to those landforms are justified, a survey is set up with the help of the ETH SelectSurvey platform. It provides 11 pages, where the first page is an introduction to the survey, the next 9 pages are dedicated to one landform per page, and the last page offers several demographic questions. The link to the offline version of the survey is provided at the Supplementary Materials section in the end of the paper. All the information received is stored anonymously and is not used beyond the scope of the survey.

\subsection{Participants}

The survey is designed for cartographers and laypersons to obtain an opinion from both experts and people dealing with maps occasionally and not necessarily familiar with relief shading. The number of respondents should be large enough (minimum 100) to minimise the subjectivity peculiar to relief shading and to obtain a clear trend in answers. The experts' opinion will be evaluated and weighted separately from the other responses.

\subsection{Questions}

At the very beginning of the survey, a collage of analytical and hand-draw relief shadings for the same area is displayed for a demonstration purpose, the latter were created at the Federal Office of Topography swisstopo [28]. On the following pages containing the questions, the respondents can match the landforms to their oblique aerial views obtained from Google Earth (Figure 1a), to have a better idea how these landforms look in reality, and they can compare the manual relief shadings (Figure $1 \mathrm{~b}$ ) to a selection of analytical relief shadings to evaluate the six methods chosen for each landform.

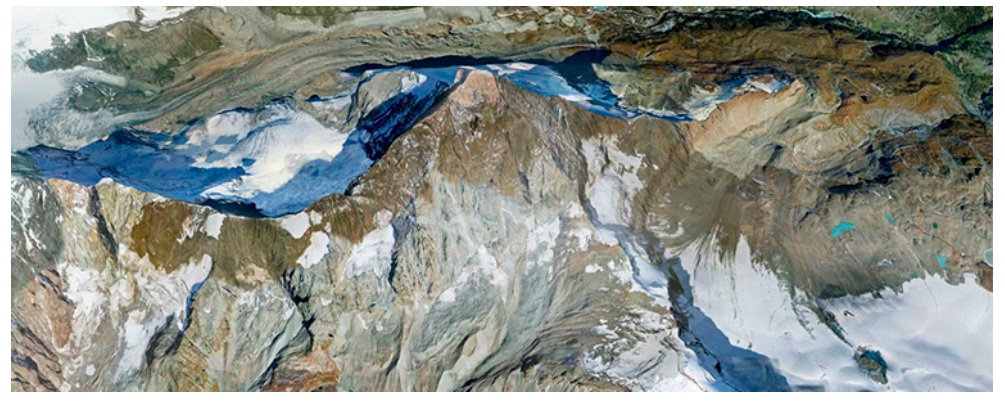

(a)

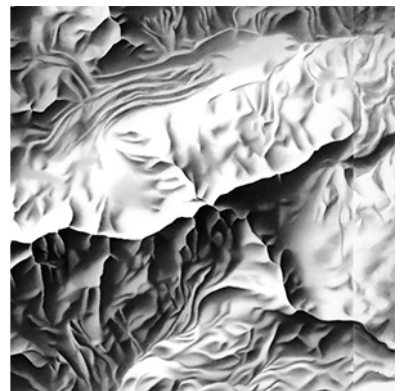

(b)

Figure 1. Block mountain sample area: (a) oblique aerial view; (b) manual relief shading.

In this survey, the authors attempt to evaluate the general look of relief shading independent of whether it is going to serve as a map background or stand out as the main map element. Therefore, the main question for the respondents is to choose the most, least, rather and rather not suitable automated method concerning a visual impression of each landform in the images. Besides, the 
participants are asked to only assess one specific landform at a time, regardless the rest of the landforms in the same image.

For statistical purposes, the standard demographic questions about gender, age and education level of the respondents conclude the survey. Two extra questions were added with the purpose to distinguish between experts and laypersons, such as the level of experience with maps and familiarity with relief shading. The latter questions are complementary, since it might be that a user creates maps but in the same time is not necessarily familiar with relief shading, or vice versa.

\subsection{Data}

Since all the landforms defined are located within Switzerland, the authors used the digital height model DHM25 [29] and manual relief shadings at 1:25,000, both the products of swisstopo. This scale was chosen to be suitable for both small terrain features like alluvial fans or drumlins, but also for mountain ridges, valleys and larger relief forms.

\subsection{Landforms Selection}

"A cartographic goal of mapping terrain is to visualize landforms and other terrain features", as noted by Kennelly et al. [17] (383). Terrain features amount to several hundred, but only the landforms related to relief shading, i.e., those repeatedly mentioned in the corresponding literature, will be taken into consideration within the confines of this work. The selection is grounded on relevance, value of landforms and their morphological characteristic. Our focus falls on larger landforms, and yet small details in the land surface need to be taken account of, since "detail brings out the character of the relief", as aptly noticed by Imhof [30] (187).

Basic terrain features to start with are mountains and valleys. These are interrelated landforms equally important for the proper terrain representation. Ridges and valleys are treated as key examples of concave and convex landforms to be distinguished between each other when light direction is changed, according to Biland et al. [31]. Also Imhof [27] considered ridges as one of the most influential elements of the surface that along with slopes, crests, edges and other linear features form cartographic skeletal lines that divide up the terrain and bring in the structure. Shaded reliefs of different mountain types (Figure 2) differ in the flattened roof-shaped ridges and uniform, moderately steep slopes for those influenced by erosion vs. sharp ridge edges for block and folded mountains.

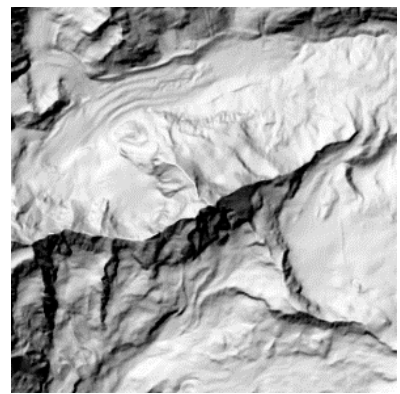

(a)

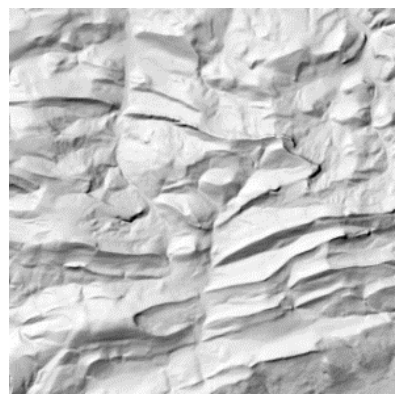

(b)

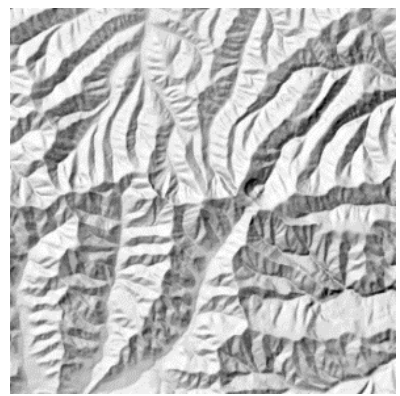

(c)

Figure 2. Standard hillshading with north-west (NW) illumination of sample areas with: (a) block mountains; (b) folded mountains; (c) mountains formed by erosion processes.

The main characteristics of block mountains are sharp ridges and a high contrast between their slopes. They comprise most of the high-altitude regions. As a sample area the authors chose the Matterhorn and its surroundings in the Swiss-Italian border region (Figure 2a). Folds form when originally flat surfaces are bent or curved as a result of permanent deformation for multiple reasons, such as stress, pressure, or temperature changes. Folds in rocks vary in size and may occur in great numbers or as isolated folds [32]. Compared to block mountains, their edges are less sharp and their 
slopes are less contrasted in tone to each other due to lower elevations. As an example, we showed the respondents a part of the Jura folded mountains in the Canton of Basel-Country (Figure 2b). Under the influence of surface processes like water flow, wind, ice, or gravity that remove rock or dissolved material and transport it to another location, uplifted areas are gradually worn down [33]. Such regions are usually significantly lower and can be considered as hilly, for instance the hilly region surrounding the Napf mountain (Figure 2c) on the border between the Swiss cantons of Bern and Lucerne. Thus, their main distinction from block or folded mountains is that ridges are generally more rounded and transitions between the slope tones are not that sharp anymore.

For valleys, it is essential to accentuate their profile and shape: steep-sided U-shaped valleys usually have a wide, flat floor (Figure 3a), whereas for V-shaped valleys on the contrary less steep slopes and narrow valleys are intrinsic (Figure $3 b$ ). V-shaped valleys are usually carved by rivers and have a V-shape in cross-section. The example below is Bergalga valley in the Canton of Grisons. In regions that remained glaciated for a long time, flowing ice erodes V-shaped valleys into steep-sided U-shaped valleys that have wide, flat, or rounded floors, as described by Imhof [27]. This type of valley is very common in the Alps and in Scandinavia. As can be seen from relief shading, the slopes of U-shaped valleys are depicted with more contrasting tones due to their steepness and they are separated by a grey tone at the bottom. A sample area here is a part of the Gredetschtal in the Canton of Valais.

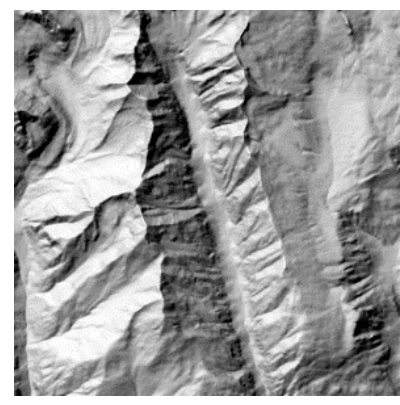

(a)

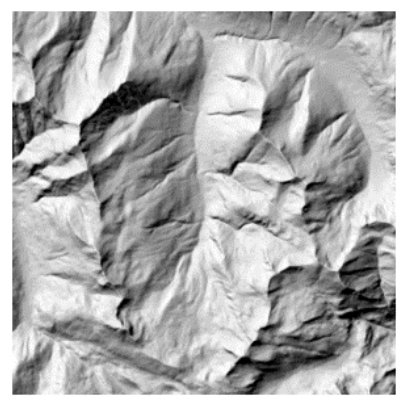

(b)

Figure 3. Standard hillshading with NW illumination of sample areas with: (a) U-shaped valley; (b) V-shaped valley.

Important characteristic of a tableland is that its flat and steep parts are represented with strong contrast to each other. Moreover, its slopes are not rounded off as for hills or mountains but are abruptly incised [27] which makes them well recognizable. Flat top parts can easily be seen in default hillshading (Figure 4a) and in an oblique aerial view (Figure $4 \mathrm{~b}$ ), although some manual hillshading examples tend to round off the top part (Figure 4c).

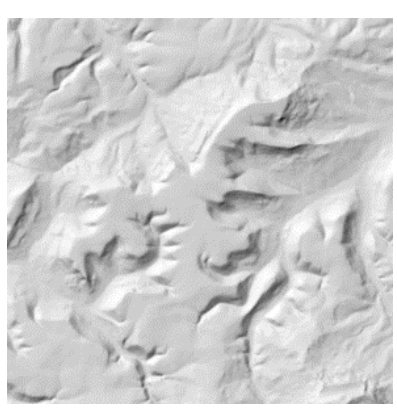

(a)

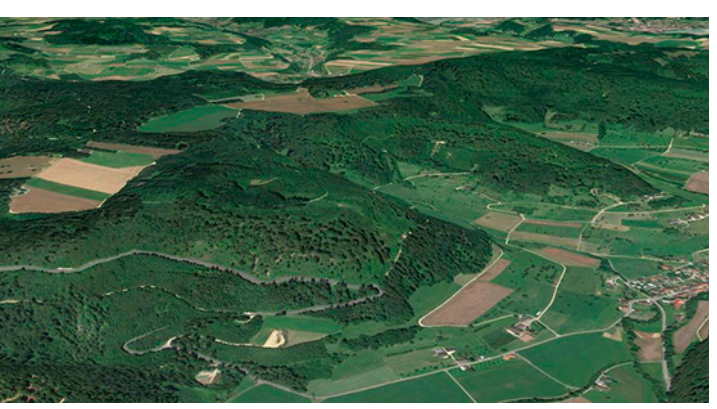

(b)

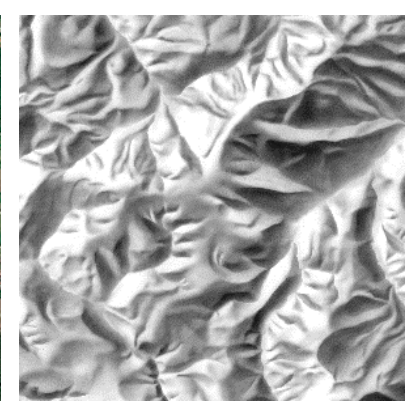

(c)

Figure 4. (a) The standard analytical relief shading with NW illumination of a sample area with a plateau; (b) an oblique view of the plateau; (c) manual relief shading of the same area by swisstopo [28]. 
The key feature in representing flat and hilly terrain is a light shadow tone produced by oblique lighting. Though this middle-tone shading may obscure topographic content or hypsometric tinting on a map, its main impact on the surface is contraposing to illuminated slopes, thereby creating three-dimensional effect, as discussed by Imhof [27]. A sample area illustrates hilly terrain in the Canton of Zurich filled with drumlins, elongated hills formed by glacial processes (Figure 5a). Their orientation coincides with the default NW direction. To attract users' attention and to enable better readability, slopes of drumlins have to be depicted with more contrast and the presence of a "ridge". Adjacent to flat and hilly areas are alluvial fans, which are deposits of water-transported material (Figure 5b). Since their main characteristic is a slope, its appearance can be improved likewise by changing the light direction to make it look more convex [25]. These alluvial fans are found in the Goms region, in the uppermost part of the Canton of Valais. For the depiction of flat areas, a middle grey tone usually performs well and is a standard according to the guidelines of the Swiss-style relief shading. Thus, flat areas are not included in the survey.

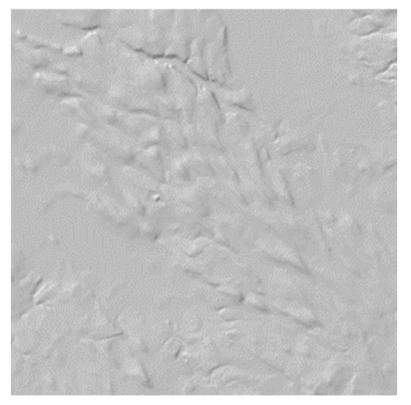

(a)

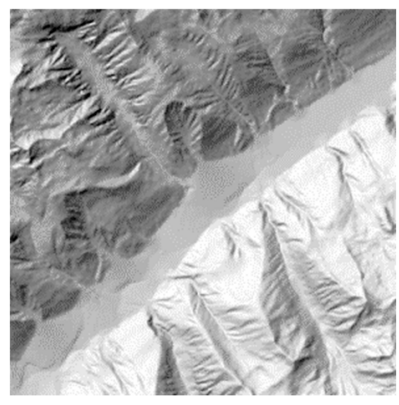

(b)

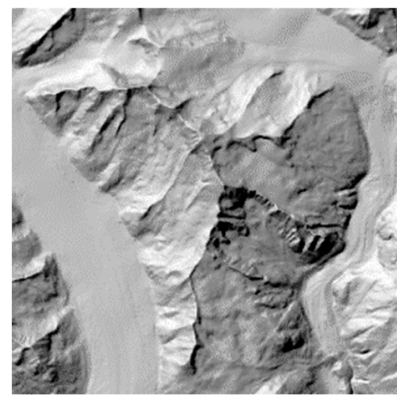

(c)

Figure 5. Standard hillshading with NW illumination of sample areas with: (a) drumlins; (b) alluvial fans; (c) glaciers.

Other landforms that make difference to linear and stretched terrain elements are glacial (Figure 5c) and lava areas. Glacial tongues and lava streams fall in with depressions and form flattened deposits. Representing regions of permanent snow involves very light shadowing that has to enable users to distinct between snowy and snow-free regions, as suggested by Imhof [27]. Besides, opposed to landforms that have to be emphasised by removing noise, glaciers need small detail to be shown on their surface to again discern them from remaining areas without snow. Ice and snow texture at glacial tongues produced by haphazard ice fractures and crevasses running across or along the glacier length, but also the shape of glacier tongue itself, bring out the characteristic look to glacial areas. The same applies to the solidified lava flows, lava swellings, run-off channels, as well as deposits caused by landslides, regions of dunes and karst areas. Due to small size of those details they can only be fetched out by symbols or in our case oblique hillshading [27]. For the survey, we chose an area of the Aletsch (on the left) and one of the Fiescher glaciers (on the right) in the eastern Bernese Alps in the Canton of Valais.

To sum up, the properties of landforms, such as sharpness of ridges or shape of valleys have to be preserved, independent of a method chosen to portray them. Keeping landforms' properties will assist in revealing and preserving differences between the basic landscape types, such as high alpine mountains, hilly terrain, plateaus, lowlands, and plains.

\subsection{Methods Selection}

Considerations on choosing methods to compare include a wide range of different techniques, yet a reasonable and limited selection to be shown to the users all at once. These methods have to be accessible and reproducible in the first place. After testing, the authors decided to settle on a maximum six images at a time (Figure 6). The order of methods applied is random and differs from landform to landform to avoid priming bias or a temptation to compare the same method across 
multiple pages when having the same order for each landform. Also, the methods applied were not communicated in captions to the respondents and were replaced by numbers, to prevent the participants from second-guessing previous responses.

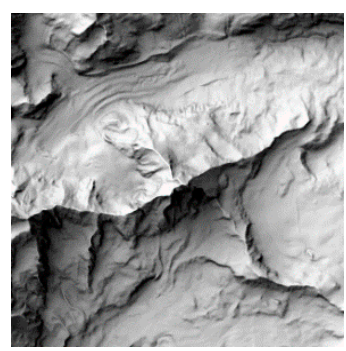

(a)

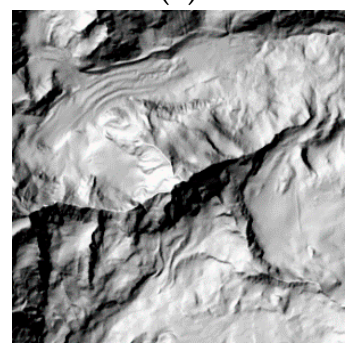

(d)

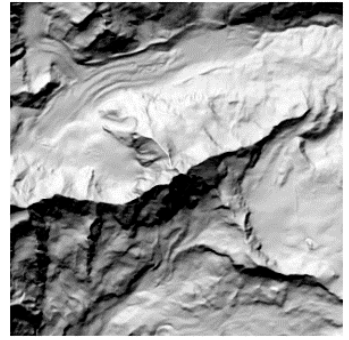

(b)

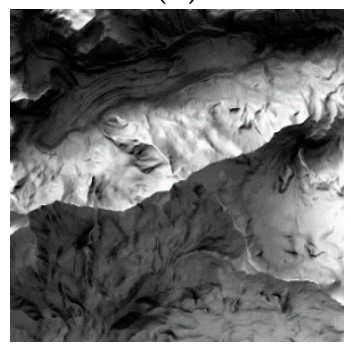

(e)

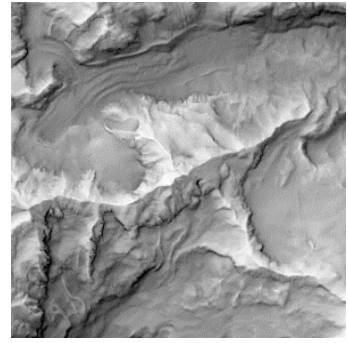

(c)

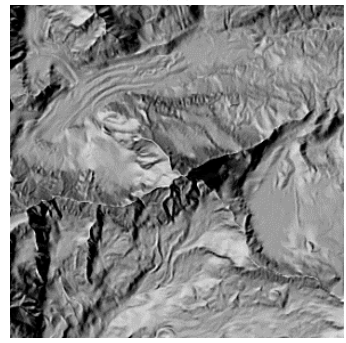

(f)

Figure 6. Methods chosen to portray block mountains: (a) clear sky model; (b) hillshading with NNW illumination, (c) texture shading, (d) cluster shading, (e) clear sky model with vertical exaggeration, (f) hillshading generated using the multidirectional, oblique-weighted (MDOW) method.

Many existing methods of analytical relief shading were automated within the Esri ArcGIS environment. For the survey, the authors used the models included in the Terrain Tools toolbox for ArcGIS, as well as SkyLum, Texture Shader and Pyramid Shader stand-alone software. This simplifies the generation of relief shadings and makes it possible for everybody to reproduce the survey images, in particular.

Since illumination is crucial in relief depiction and most of the methods designed over time had a focus on lighting, the authors chose to test various lighting approaches:

- $\quad$ single-point, directional illumination

- multiple-point illumination

- changing light direction

- $\quad$ sky model illumination

To deploy a single-point illumination, we generate hillshading with the light coming from the improved north-northwest (NNW, 337.5 $)$ instead of the standard illumination originating from the north-west $\left(\mathrm{NW}, 315^{\circ}\right)$, as it is claimed to provide better relief shadings with the respect to relief inversion effect [31].

As a multiple-point illumination the authors chose the multidirectional, oblique-weighted (MDOW) model developed by Mark [23] and also implemented within the ArcGIS Terrain Tools. It results in a hillshading as a combination of shaded relief images illuminated from four weighted illumination directions $\left(225^{\circ}, 270^{\circ}, 315^{\circ}, 360^{\circ}\right)$, which ensures enhancing ridges and valleys stretching parallel to the general aspect direction of illumination. Generally, it proved to perform better at large scales, and in this survey is evaluated at the scale 1:50'000.

Cluster shading [25] creates a seamless change of local lighting conditions, building areas with similar aspect. This enables the extraction of major landforms, defining larger landforms and avoiding sharp boundaries. For the survey, only the general Cluster Hillshade tool from the Terrain Toolbox is used. 
With the help of the SkyLum we apply illumination sources from 250 points to approximate a sky model [17], in order to enhance details on parts of terrain facing away from the illumination direction and adding soft shadows to terrain maps. Out of five sky models embedded in the application (uniform, overcast, clear, sharp, and turbid), the clear sky produced visually proper results for all the landforms. Two non-directional models either resulted in darker cast shadows (uniform) or are usually recommended for deep areas like canyons (overcast), but not for all the landform types, as discussed by Kennelly et al. [34]. While the directional sharp sky model reminds one more of a single point source illumination, as the sharp sky is only bright in the direction of the sun and diminishes in brightness very quickly being further from the sun. Turbid and clear skies are similar, with the difference that a turbid model offers more illumination close to the horizon, and valleys appeared with a generally darker tone compared to clear sky output. The authors also included the resulting shaded relief with the vertical exaggeration of five times (5x), as suggested by the developers of the SkyLum application [17]. The clear sky model was thereby chosen for the survey.

Finally, the Terrain Texture Shader stand-alone application was used, as this method proved to bring out the drainage structure of terrain that is dominated by a strong ridge and canyon network, in particular [35].

For some landforms, several extra methods were deployed to generate reliefs, as they demonstrated visually interesting and more appealing results. In particular, for drumlins, U-shaped valleys, and alluvial fans, the authors proposed a custom illumination direction instead of the NNW illumination, which was dictated by the orientation of the landforms. Local hypsometric tints method introduced in the Pyramid Shader software as "local hypsometric color" and described by Huffman and Patterson [36] was applied to drumlins and replaced shaded relief generated using a clear sky model with vertical exaggeration for two reasons: 1) the local hypsometric tint method revealed a fine linear structure of drumlins, whereas 2) vertical exaggeration changed the impression of drumlins making these small landforms (compared to mountains and valleys) looking rather artificial, being scaled vertically. The same reasoning was employed in relation to glaciers: aspect shading experimentally showed successful portraying of glacial texture, and visually outperformed compared to the clear sky model with vertical exaggeration. The minor artefacts of the aspect shading output were corrected on a pixel level, in order to prevent the respondents from being distracted by them. Below, is the complete list of methods (Table 1) in the order they appear in the survey.

Table 1. Landforms and methods chosen for the survey.

\begin{tabular}{ll}
\hline Landforms & Methods \\
\hline Block mountains & $\begin{array}{l}\text { (1) clear sky model, (2) standard hillshading with NNW illumination, (3) texture shading, (4) cluster shading, } \\
\text { (5) clear sky model with vertical exaggeration, (6) MDOW }\end{array}$ \\
Folded mountains & $\begin{array}{l}\text { (1) MDOW, (2) texture shading, (3) cluster shading, (4) clear sky model, (5) clear sky model with vertical } \\
\text { exaggeration, (6) standard hillshading with NNW illumination } \\
\text { (1) clear sky model, (2) texture shading, (3) MDOW, (4) cluster shading, (5) standard hillshading with NNW }\end{array}$ \\
Mountains formed by & $\begin{array}{l}\text { illumination, (6) clear sky model with vertical exaggeration } \\
\text { erosion processes }\end{array}$ \\
Drumlins & $\begin{array}{l}\text { (1) cluster shading, (2) clear sky model, (3) standard hillshading with NE illumination, (4) MDOW, (5) texture } \\
\text { (1) clear sky model, (2) standard hillshading with NNW illumination, (3) texture shading, (4) clear sky model }\end{array}$ \\
Plateaus & $\begin{array}{l}\text { with vertical exaggeration, (5) MDOW, (6) cluster shading } \\
\text { (1) texture shading, (2) clear sky model, (3) MDOW, (4) cluster shading, (5) clear sky model with vertical }\end{array}$ \\
V-shaped valleys & $\begin{array}{l}\text { exaggeration, (6) standard hillshading with NNW illumination } \\
\text { (1) MDOW, (2) clear sky model with the south (S) illumination, (3) cluster shading, (4) clear sky model with S } \\
\text { illumination and vertical exaggeration, (5) clear sky model with NW illumination, (6) texture shading. } \\
\text { (1) texture shading, (2) standard hillshading with W illumination, (3) clear sky model with vertical }\end{array}$ \\
Alluvial fans & $\begin{array}{l}\text { exaggeration, (4) clear sky model, (5) MDOW, (6) cluster shading } \\
\text { (1) clear sky model, (2) aspect shading, (3) MDOW, (4) cluster shading, (5) texture shading, (6) local } \\
\text { hypsometric tints }\end{array}$ \\
Glaciers &
\end{tabular}

\section{Results}

The survey yielded 151 complete responses and 42 incomplete ones that were not used for the analysis. Duration of the survey varied greatly from $5 \mathrm{~min}$ to $6 \mathrm{~h}$ and $20 \mathrm{~min}$ with an average duration of completed responses equal to 17:20 min, which is a bit longer than the estimated time of 
15 min suggested in the introduction to the survey. All the results are available for download as the supplementary data.

\subsection{Participants}

The 151 people completed the survey, in particular $113(73 \%)$ male, 39 (25\%) female respondents, and two participants who preferred not to communicate their gender. A greater part of the responses, $47(31 \%)$ and $42(27 \%)$, was received from persons aged 25-34 and 35-44 years old, respectively. The other respondents' age groups were $45-54$ years old, 26 (17\%), 23 people over $55(15 \%)$, and 15 participants aged 18-24 (10\%); one person preferred not to indicate their age. Most of the people who completed the survey have a master's $(54 / 35 \%)$ or a doctoral $(47 / 31 \%)$ degree, while the rest of the interviewed persons' highest level of education is a bachelor's degree (23/15\%), a professional degree $(11 / 7 \%)$, a high school degree or equivalent $(14 / 9 \%)$, or less than a high school diploma ( 3 or $2 \%)$; two people preferred not to say. The respondents evaluated their experience with maps as follows: $83(54 \%)$ of them create maps, $37(24 \%)$ deal with maps on a daily basis, the other $28(18 \%)$ use maps weekly, while $6(4 \%)$ use maps rarely. These numbers show that the survey reached its target audience, but also gave the possibility to obtain feedback from non-cartographers. The respondents indicated in "\%" their familiarity with relief shading, and on average, it amounts to $68 \%$; 56 participants were $80 \%-100 \%$ familiar with relief shading (of whom 28 indicated $100 \%$ ) and thus formed the experts group; 42 respondents indicated more than $50 \%$ and 23 less than $50 \%$, including 9 people who were not familiar with relief shading at all.

\subsection{Answers}

Obtaining additional survey results as detailed qualitative comments allowed for explanations which characteristics or aspects respondents took as a basis for evaluation, why they made specific choice, what difficulties they experienced when answering the questions, and provided suggestions of what can be improved and, generally, ideas and observations.

\subsubsection{Block Mountains}

As may be seen from Figure 7, almost the half of the respondents (47\%) chose the clear sky model method as the most suitable for the depiction of the block mountains. Relief shading with NNW illumination was mainly considered rather suitable whereas texture shading rather not (32\%) or least suitable (29\%) for portraying the landform. Cluster shading received $44 \%$ of the answers as being rather suitable, while the MDOW method was considered to be rather inappropriate for this landform ( $29 \%$ for rather not suitable and $29 \%$ for least suitable). The most controversial method appeared to be the clear sky model with vertical exaggeration, since it scored high enough numbers in each of the categories: $31 \%$ believed it is actually the most suitable method, $18 \%$ rather suitable, $16 \%$ could not decide, $25 \%$ rather not suitable, and $10 \%$ the least suitable method for depicting this landform.

The numbers above largely correspond to more than 40 comments left to this question. Most of the respondents emphasized that the texture shading method gives a very flat impression and does not allow for recognizing the peak and height differences, although it reveals or highlights structures hidden in other images. It also contradicts to the aerial perspective effect, since its darkest parts on the shadowed slopes filled the feet of the mountain instead of their peaks. Besides, it looks soft enough to lose detail. Another likely unsuitable method for this landform is MDOW. This method gives the impression that the landscape is less steep than it seems in all of the other examples, it does not capture the overall impression of the hand-drawn version, has excessive detail in the lowest part of the slopes and lacks expressiveness at the peaks. Several respondents called this shading "plastic" or even looking fake; the others, on the contrary, noted that the higher level of detail was valuable and appealing to them, and assisted them in reading the terrain. The influence of vertical exaggeration applied to the digital elevation model before generating the hillshading can be fully assessed in the comments of the users. While some of them claimed that it is generally too dark, particularly in its 
northern valley, and there is not enough contrast between the slopes, at the same time it gives the most engaging and realistic impression for many participants and was recommended for depiction of larger relief forms. The NNW and cluster shading images delivered not only visually very similar results, but also similar comments: most of the participants distinguish the best grey-scale contrast leading to a better readability of larger forms and clear light shadow contrast that help to reveal more detail on shadowed slopes, but also note they are a bit too sharp compared to other examples. The main difference between the two is that cluster shading allows for better readability of the minor slopes, but on both images black spots in shadows hide information about relief, which is their major drawback compared to the first method. Finally, most respondents marked the clear sky model method as the best way for depicting the block mountains, as it provides the most balanced contrast, it is not overly detailed and also has a broader shadow and illumination area accentuating the larger forms. At the same time, several participants consider it looking a little too flat compared to the two previously discussed techniques.

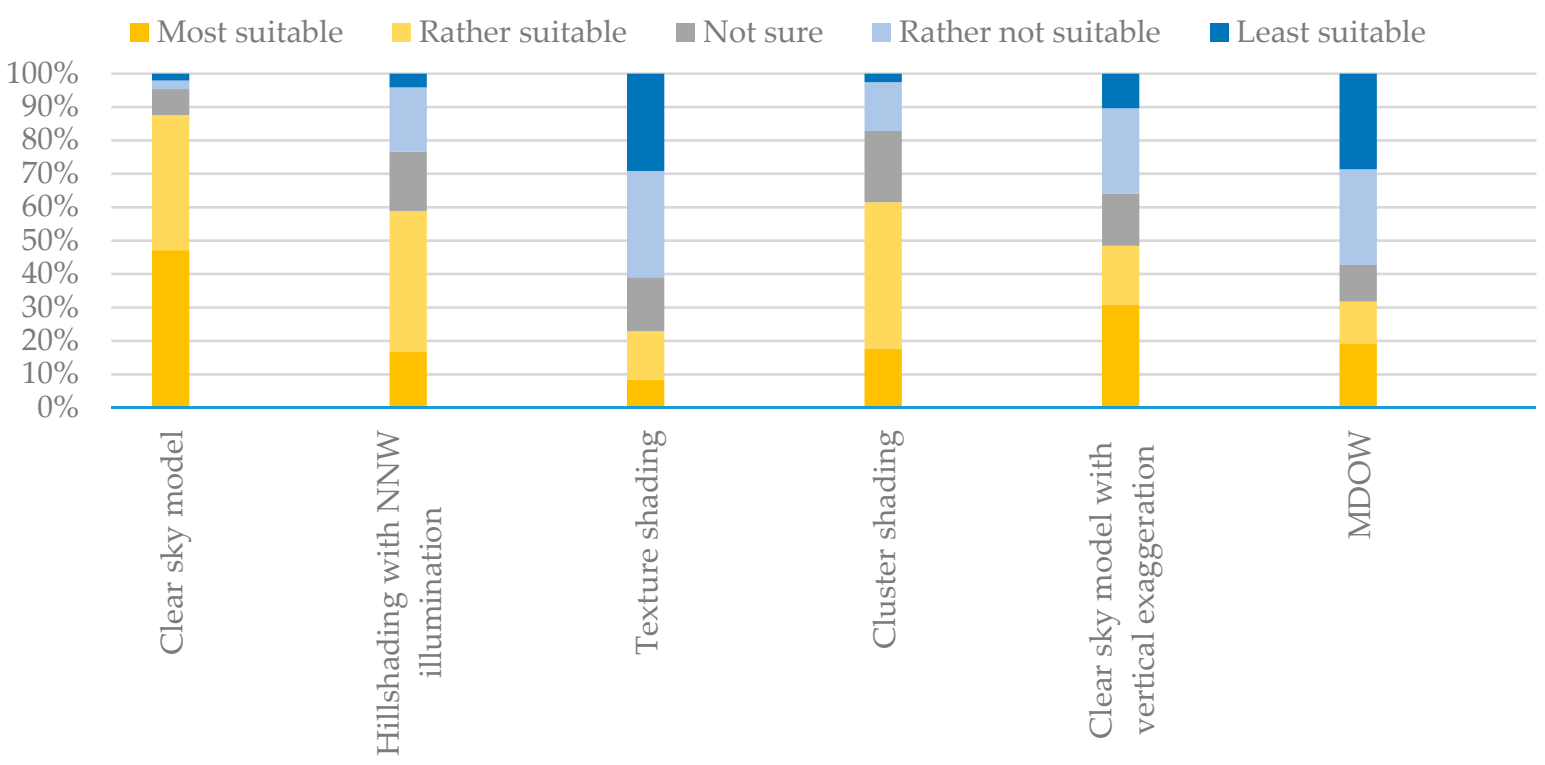

Figure 7. Survey results for block mountains.

The experts' opinion is solid here, they likewise gave preference to the clear sky model method emphasizing that it has a full tonal range, good contrast without saturation, its shadows and illumination nicely define the pointy top of the Matterhorn, and it also has broader shadows and illumination that shows the entire ridge that the Matterhorn sits on. Several experts also appraised the cluster shading highly and recommended it on a par with the clear sky model or tended to prefer to add vertical exaggeration prior to applying the clear sky model, which brings more 3-dimensionality.

\subsubsection{Folded Mountains}

When choosing between the methods to depict folded mountains, the respondents gave more scattered answers (Figure 8). For the folded mountains based on the presented images, the MDOW and texture shading methods were substantially considered as rather not (38\% and $33 \%)$ or least suitable ( $23 \%$ and $33 \%$, respectively). Nearly the half of the participants ( $48 \%$ ) agreed that the cluster shading is a rather suitable method. A greater part of the respondents gave the preference to the clear sky model, saying that it is either the most (31\%) or rather suitable (46\%) method. In combination with the vertical exaggeration, the clear sky model gained $35 \%$ of all the answers for being the most suitable method to apply to this landform. Lastly, the NNW scored the third of all the votes (36\%) to be a rather suitable method along with the both clear sky model methods. 


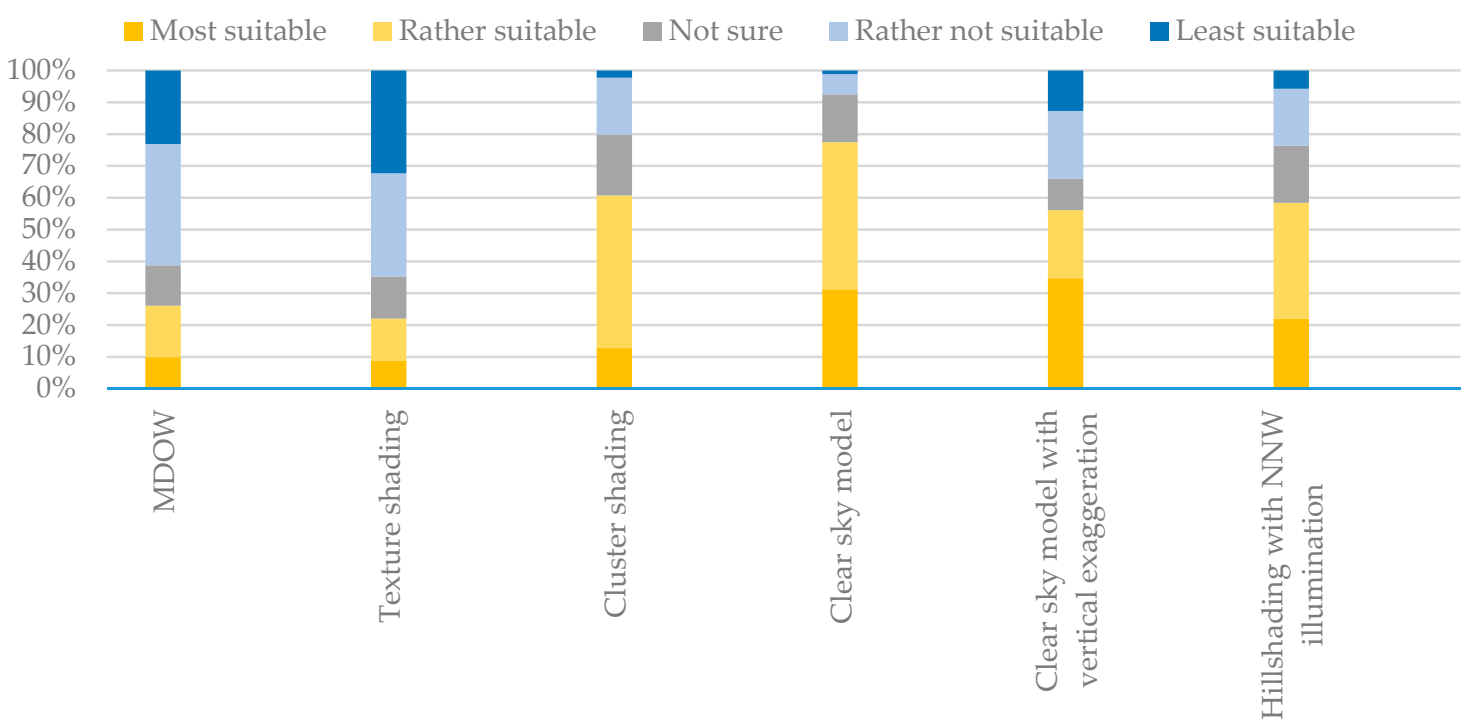

Figure 8. Survey results for folded mountains.

After a closer look at the numerous comments of the participants, we can make the following conclusions. As in the case with block mountains, the MDOW method delivers generally a too noisy image with little details disturbing the whole relief shading and preventing the map readers from recognizing the main relief structures and forms and interpreting the relief as a whole. Cluster shading was generally commented upon in a rather positive way in that it has a nice contrast balance and is easy to read without changing the contrast, but it was also noted that larger forms look disintegrated. The clear sky model, both with and without vertical exaggeration, received the most positive feedback from the participants. Without vertical exaggeration, it provides the best contrast, makes it easier to identify the larger forms, and overall is less noisy than other examples. While with vertical exaggeration, despite too much contrast and dramatic effect, it attracted the respondents by its expressiveness and the strong sense of three-dimensionality, form and folding that it produces. Although the NNW illumination was considered rather suitable to apply to the folded mountains, it lacks the contrast and aerial perspective effect.

The expert opinions here vary, mainly between the sky model with and without vertical exaggeration. The clear sky model method was commented upon as the one that has a full tonal range and the right amount of white illumination and black shadows near the top of the highest ridges where it is needed most, whereas the vertical exaggeration conveys expressiveness and reveals most of the relief; at the same time, it exaggerates the heights and gives the impression of higher mountains, while many respondents like softer shadows for this type of relief. The texture shading method with regard to depiction of folded mountains shows too little contrast differences, thus preventing the users from understanding the heights, and better conveys the steepness of the slopes than the type of terrain. Cluster shading generates the darkest areas on shadowed slopes.

\subsubsection{Mountains Formed by Erosion Processes}

As in the two previous cases, prevailing number of the respondents answered that the clear sky model generates the best shading also of the lower mountains formed by erosion processes (Figure 9). Texture shading and the MDOW method were considered to be unlikely suitable for this purpose. Cluster shading was overall regarded as favourable method for this type of the terrain, and a little less was the hillshading with NNW illumination and the clear sky model with vertical exaggeration, respectively. Although, the latter received the second highest number of answers as the most suitable technique. 


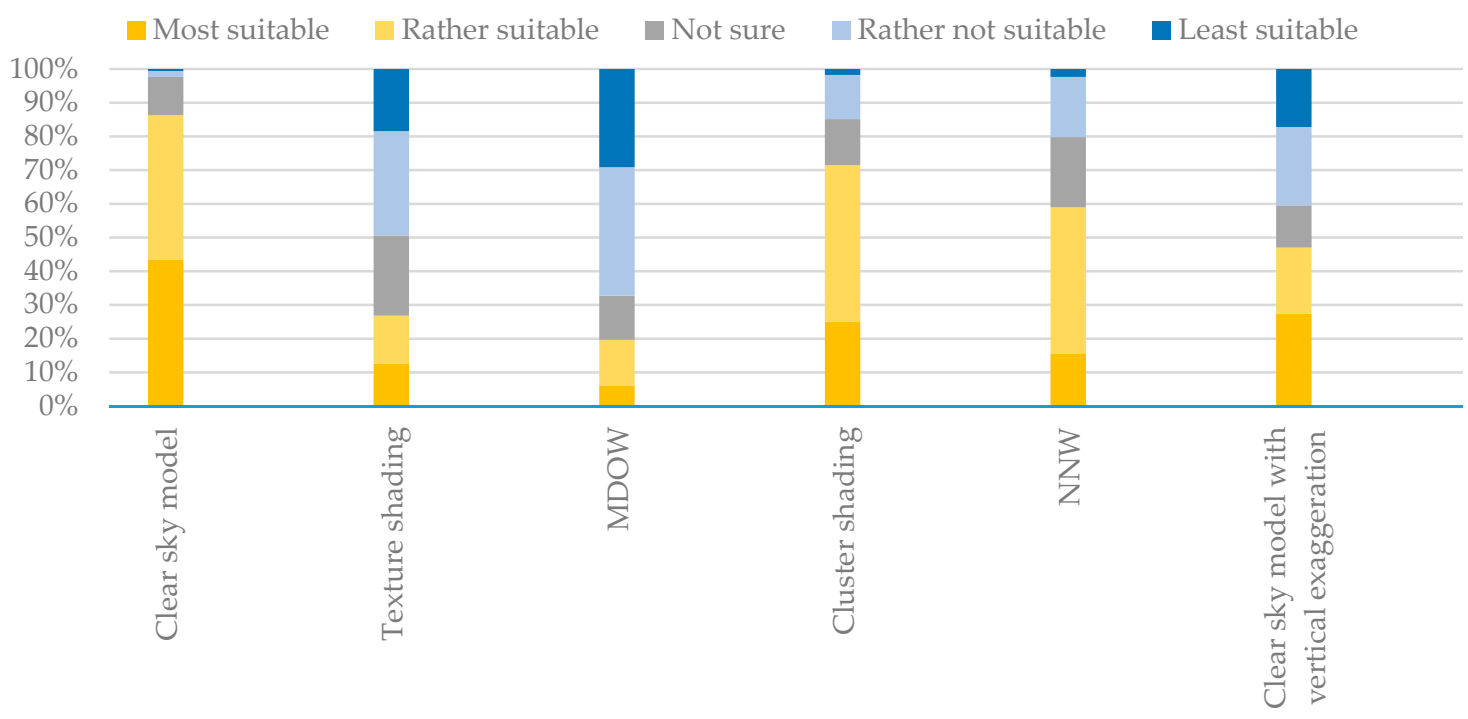

Figure 9. Survey results for mountains formed by erosion processes.

Based on the comments of the participants, both clear sky model method and cluster shading provide good contrast allowing for grasping topography and recognition of larger forms. Increasing the vertical scale, according to most respondents, gives too rough an impression and makes the mountains look too exaggerated and fairly higher than in reality, although it emphasizes ridges and valleys well, which helps to read the terrain in an intuitive way. More even histogram tones produced by NNW illumination make a softer effect but still let the participants read the terrain easily. The terrain texture shading, as in the previous cases, is too light and not eloquent enough for differentiating the heights and relief forms, but is certainly suitable as a basemap. Finally, the MDOW method was claimed not to have the same level of detail as other examples, the aerial perspective effect is missing on it, and several respondents called it an aluminium foil due to its metallic look.

In relation to this landform, the opinion of the experts was not unanimous anymore. Each of the six methods was chosen as the most suitable by one or another expert. One of the critical issues mentioned was the relief inversion, which is present in all the methods shadings to some extent, except for the texture shading and the exaggerated clear sky model. As it is one of the worst drawbacks a shaded relief may have, the users may even prefer an exaggerated terrain over that suffering from relief inversion. The other part of the experts would rather use the texture shading with fewer deep shadows but remaining detail, so that they could easily complement it with other thematic data. Some of the experts believe that none of the shadings presented show the large relief forms or balanced contrast like the manual example.

\subsubsection{Drumlins}

With respect to drumlins (Figure 10), equal parts of the respondents (each $30 \%$ ) suggest that cluster shading and the clear sky model are the best two methods to portray the drumlins. The rest of the four techniques each yielded less than $10 \%$ of the answers, out of them the participants preferred the standard hillshading with NE illumination over the other three methods.

In their comments, the participants explained, that none of the suggested methods could perfectly cope with the task to visualize the flow direction of the glacier, on the one hand, and to keep the individual shape of the drumlins, on the other hand. The first two methods make the best impression, since they show the relief of the terrain, the direction of the slopes, and preserve the rounded shape of the drumlins.

The expert group delivered miscellaneous comments with regard to depiction of drumlins. Based on their common opinion, the clear sky model is the most appropriate method to depict drumlins, as it produces the most balanced shading, and also the rounded shape of the drumlins better resembles their 
natural look like on the Google Earth image (although not the manual relief shading). The standard hillshading with the NE illumination provides a nice pattern, but its 3D effect is subtle. Several respondents recommended to either apply multiple light sources or NE illumination when generating the shading using the clear sky model, in order to reach the best visual effect. Local hypsometric tints make drumlins look too narrow and linear. The MDOW could be an appropriate technique for drumlins, if it would not bring the excessive detail in flat areas, that disrupt the overall pattern and might also distract the map user. Generally, on most of the shadings (except the standard hillshading) the grey value in flat areas is too dark, and without adjustment, none of these images would be directly usable.

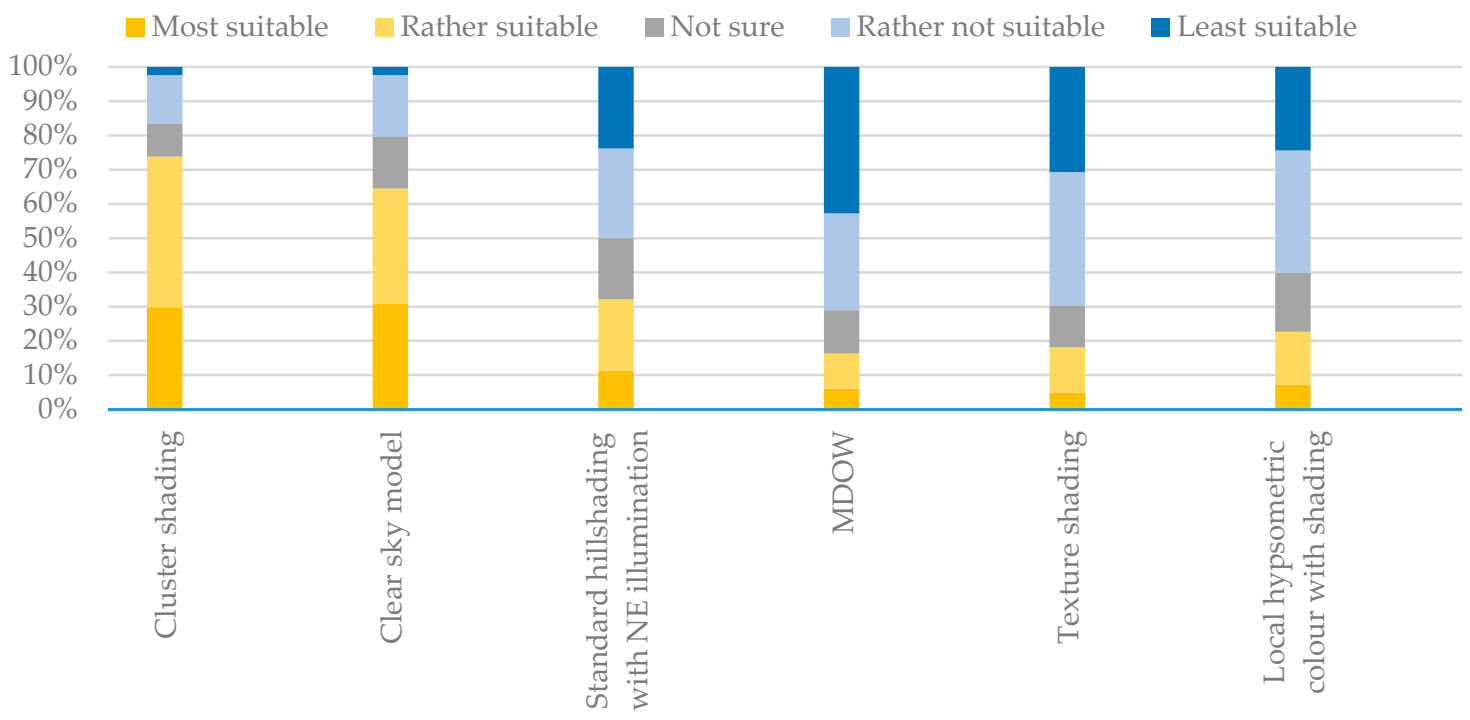

Figure 10. Survey results for drumlins.

\subsubsection{Plateaus}

The most suitable method for plateaus appears to be a difficult choice for most of the respondents (Figure 11). There is no unanimous opinion among both non-cartographers and experts. With a slight superiority, clear sky model with and without vertical exaggeration and standard hillshading with NNW illumination make a better impression of the relief of the plateaus.

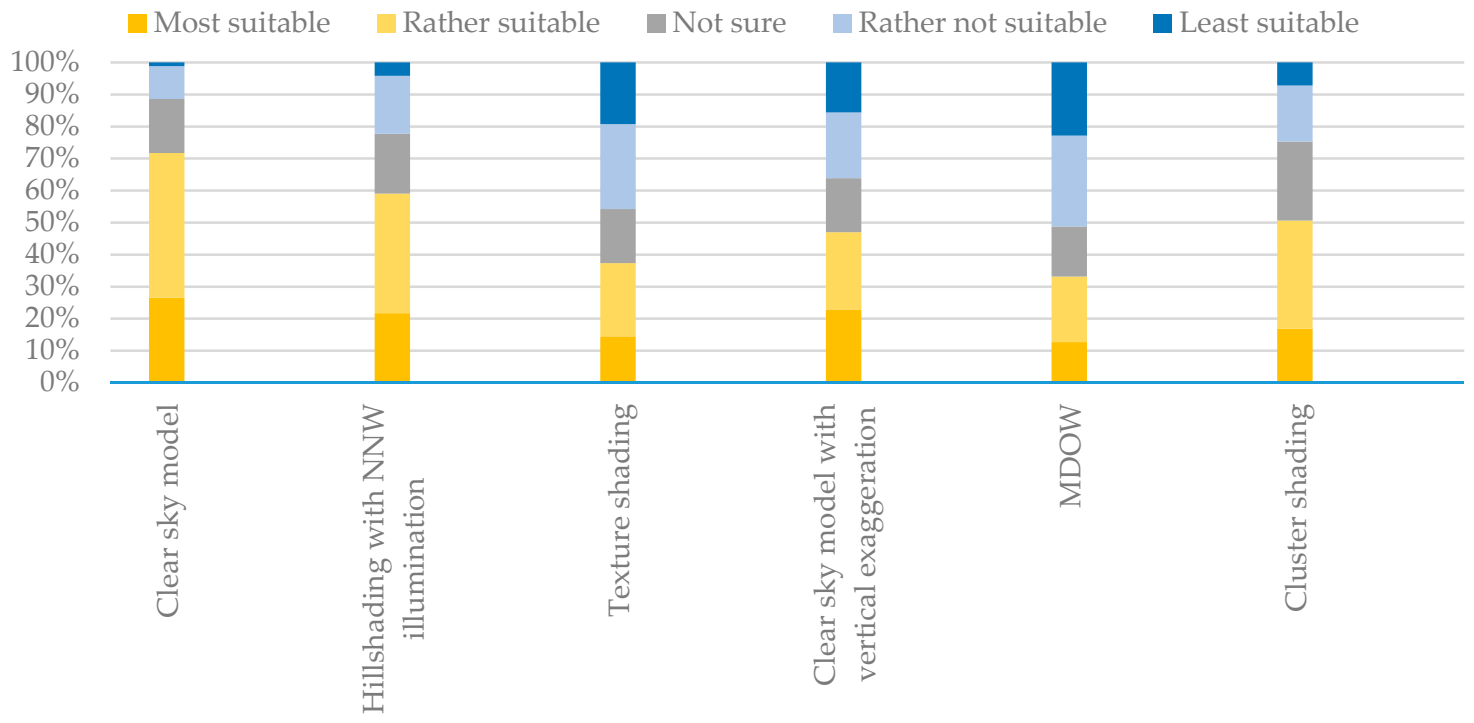

Figure 11. Survey results for plateaus. 
Analysis of the comments gives a better idea of respondents' reasoning. Those who gave a preference to the clear sky model claimed that its stronger shadows and flat upper areas draw out the landforms in the best way, that this method provides the best interplay of terrain elements, and brings a natural look to the terrain. The same method in combination with altering the vertical scale of the terrain looks more pronounced than even the hand-drawn version, is very clear with regard to overall terrain, and has a stronger three-dimensional effect, as happens when relief becomes deliberately exaggerated. On the other hand, it is certainly extreme and dramatic, as noted in every second comment. Clear sky model and cluster shading images reportedly look too similar to tell them apart which is, first, interesting and, second, is only the case with the plateaus. Apparently, for this reason they were evaluated in a similar way. Texture shading shows the pattern of a plateau well but looks too flat to the great part of the participants, and the MDOW method starts to look like a foil once again.

Several experts noticed that the manual relief shown here does a poor job at depicting the plateaus, making the top parts of the plateaus rounded instead of flat. Thereby, most analytical shadings here deliver better result than the manual one. A mix of the top part with the vertical exaggeration with the lighter incised part as that one provided by the standard hillshading, was suggested as a possible improvement.

\subsubsection{V-Shaped Valleys}

Despite its exaggerated contrast and overall look, the $40 \%$ of the respondents found the clear sky model shading with vertical exaggeration generally more appealing for V-shaped valleys compared to the other examples (Figure 12). Without increasing the vertical scale, the clear sky model method produces the best shading, according to a quarter of the respondents. Very close (21\%) is texture shading, which this time proved to deliver proper shading for this type of terrain. Both cluster shading and standard hillshading with NNW illumination look least pronounced with respect to V-shaped valleys.

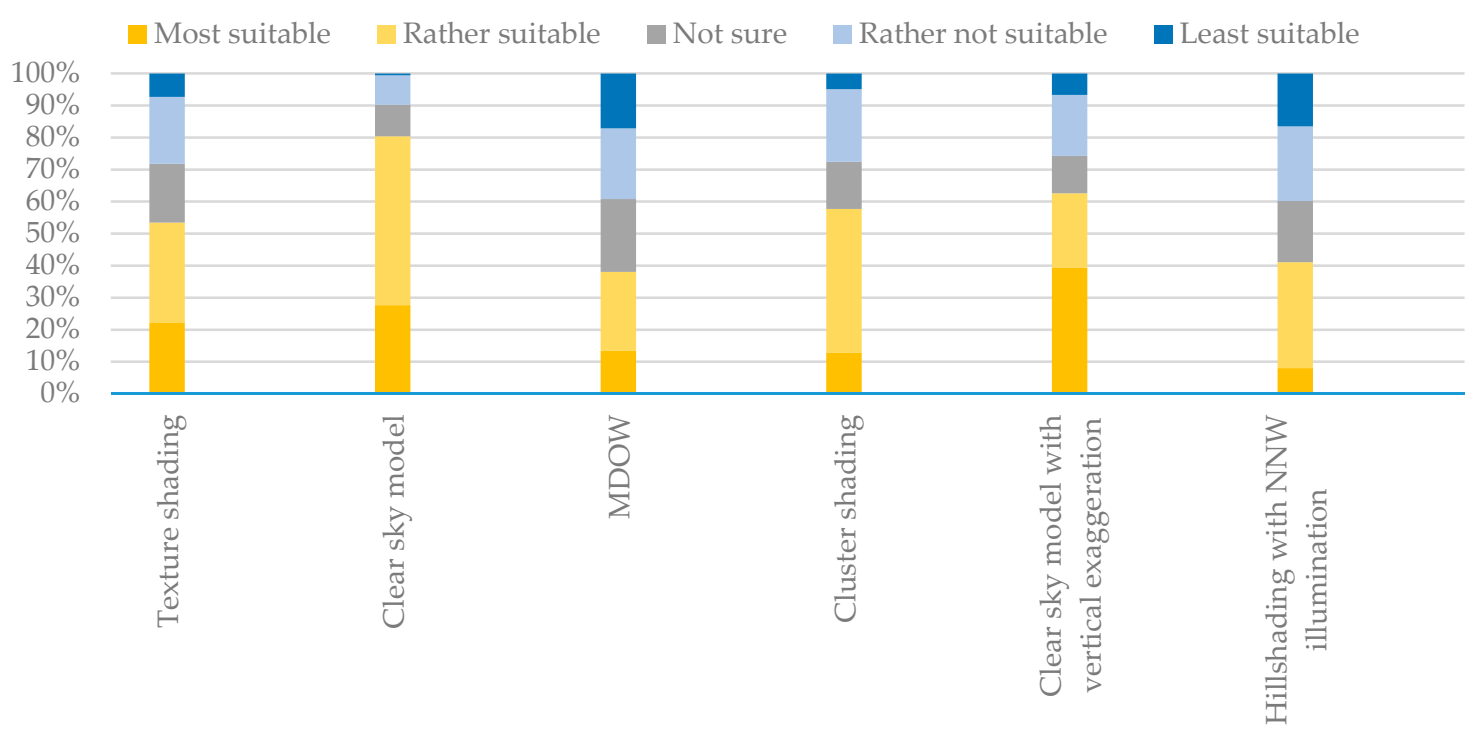

Figure 12. Survey results for V-shaped valleys.

According to the respondents' comments, the relief inversion appeared to be a big problem present at this terrain again, including the manual relief. To some participants, the manual example looked unusual and sophisticated as a reference. The MDOW shading once again looks overly detailed to many and has a metallic effect. The main deficiency of the standard hillshading here is that, despite the adjusted NNW illumination, it reportedly lacks contrast and thus clarity when distinguishing the larger forms. In contrast, cluster shading proved to have better emphasized the ridges. Texture shading brings more contrast and darker tones in the valleys, and as a result prevents the relief from 
inversion and accentuates the heights. As for the clear sky model alone, the respondents agree that the generated relief has appropriate balance in shading and more accentuated ridges, but vertical scale changes make it possible to better emphasize also slopes as a part of larger relief forms.

The experts could not help but notice that excessive dimming in the valleys, brought by the increased vertical scale, contradicts the aerial perspective effect on the shadowed slopes, where the darkest tones should appear at the highest parts next to the ridges and not down in the valleys. Even though the darker lowland tones prevent the shading from relief inversion, it would be hard to use such a high contrast relief on a map, as noted multiple times. Larger forms are not well developed in all the examples, and none of the shadings clearly shows the bright and the dark slopes of the valley. But a combination of more pronounced ridges, generated by a clear sky model or cluster shading, with the well-distinguished large slopes, which is possible due to increasing the vertical scale, would bring a substantial improvement in this case.

\subsubsection{U-Shaped Valleys}

One third of the respondents preferred clear sky model with the south illumination, i.e., light direction perpendicular to the direction of the valley, for the depiction of U-shaped valleys (Figure 13). The same method combined with the vertical exaggeration, the MDOW and the clear sky model with the standard NW illumination received each about the same $20 \%$ of the votes, while texture and cluster shading do not look that favourable for portraying U-shaped valleys.

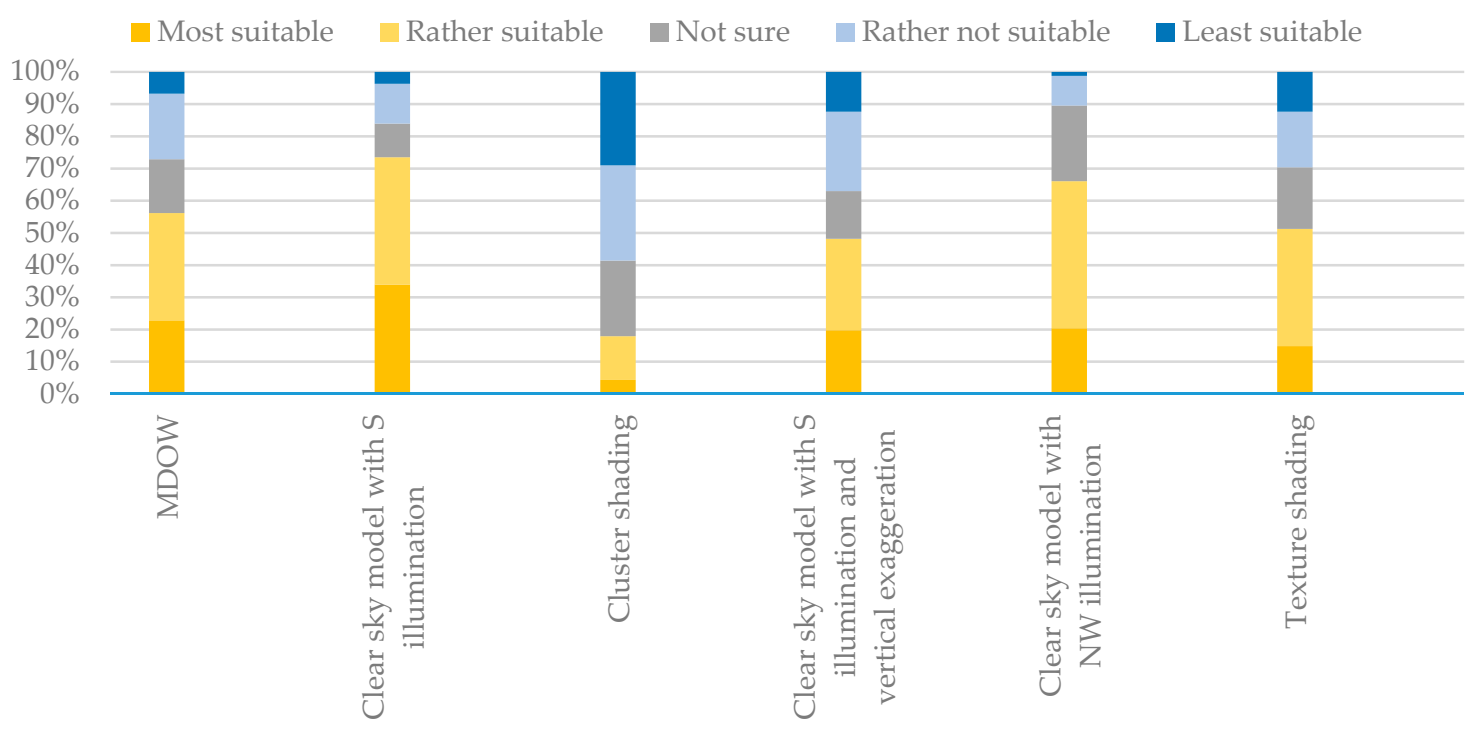

Figure 13. Survey results for U-shaped valleys.

Based on the respondents' comments, the south illumination brings an appealing look of the U-shaped valley, expressed in well-balanced grey tones, in the intuitive recognition of the relief forms, and in a characteristic roundness of the valley, which is peculiar to this landform. The NW illumination works also well for this type of valleys and properly accentuates the steep sides, despite the black stripe down the slope stretching parallel to the valley floor. The MDOW method reveals too much detail, while texture shading does not look very eloquent in achromatic tones and suits better for colour relief shading. Cluster shading does not capture the flat floor of the valley very well and has too dark a slope, which contributes to the fragmentation of the image. Finally, changes in vertical scale provide stronger contrast and represent a steeper and narrower valley floor, which is misleading with regard to a U-shape and give more impression of a V-shape. It also raises the same issue with the aerial perspective effect, as in case with V-shaped valleys. 
Another example showing that the hand-drawn relief is not always superior to digital relief is the $\mathrm{U}$-valley floor that appears wide in all the examples, except in the hand-drawn one, as aptly noticed by the experts.

\subsubsection{Alluvial Fans}

One third of the respondents considered the hillshading with the light direction from the west, i.e., perpendicular to the alluvial fan slope, the most successful solution to accentuate alluvial fans (Figure 14). The other significant part of the participants (18\%) decided that also the MDOW method performs well in this case. The rest of the methods were not very convincing, and the respondents could not explicitly decide between them.

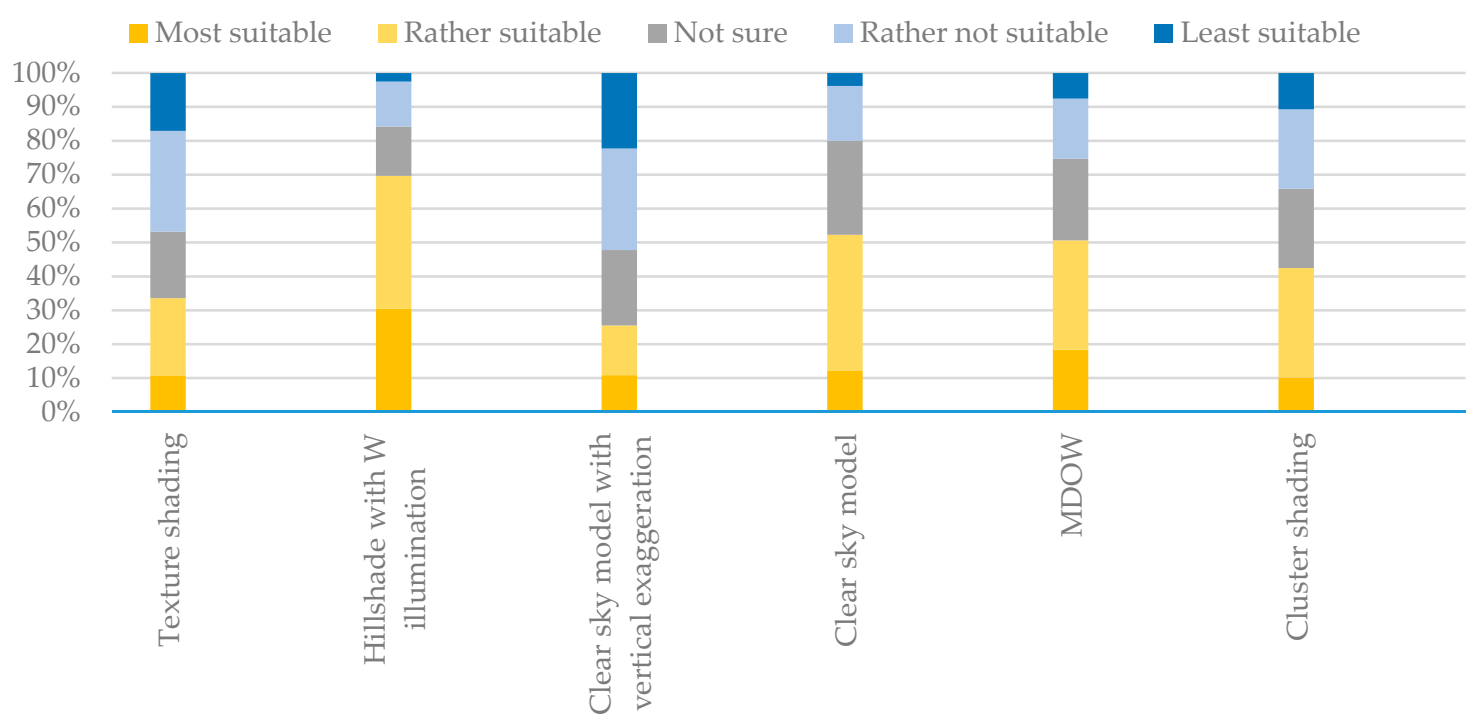

Figure 14. Survey results for alluvial fans.

There are not many comments from laypersons, except that several people noted that none of the examples is particularly successful in depicting alluvial fans. The experts generally shared the same opinion. They mentioned that it is difficult to only look at these little geomorphological forms without considering the rest of the terrain, and that showing them separately would require a hillshading with terrain segmentation. Relief inversion was also the case with alluvial fans. The experts commented on differences between the methods as follows. The MDOW method provides the most fan detail and variation in the features in the valley floor. Vertical exaggeration in the clear sky model method makes it difficult to distinguish the fan from the edge of the mountains due to its darkness. The texture shading looks too flat, while both the valley floor variation and the hillsides are most evident in the hillshading with the western illumination, clear sky model, and cluster shading. The possible improvements offered are post-processing of alluvial fans, changing a data source to light detection and ranging (LIDAR) data instead of a DEM, and adjusting the light direction so that it does not coincide with the direction of the fans slopes.

\subsubsection{Glaciers}

More than $40 \%$ of the respondents (Figure 15) chose aspect shading as the most suitable method to apply to glaciers. A clear sky model, MDOW and cluster shading received overall a positive feedback, too, while texture shading and local hypsometric tints techniques most participants found to be least suitable for this purpose.

Despite an impressive level of detail and preservation of the flow marks on the surface, the aspect shading was also commented on as a very sharp, exaggerated method depicting a specific state of a glacier, as it is usually always in motion. A clear sky model and cluster shading bring out less detail 
on the surface of the glaciers' surface, thus are not overloaded. Concerning the MDOW method, the participants commented that it shows the flow of glaciers nicely. Texture shading reveals a mountainous structure and glaciers very nicely, but the difference between snowy patches and snow-free area is not always clear nor correctly depicted. The glacier texture produced by local hypsometric tints, as well as by cluster and texture shadings, almost reminds one of a water surface instead of an ice surface.

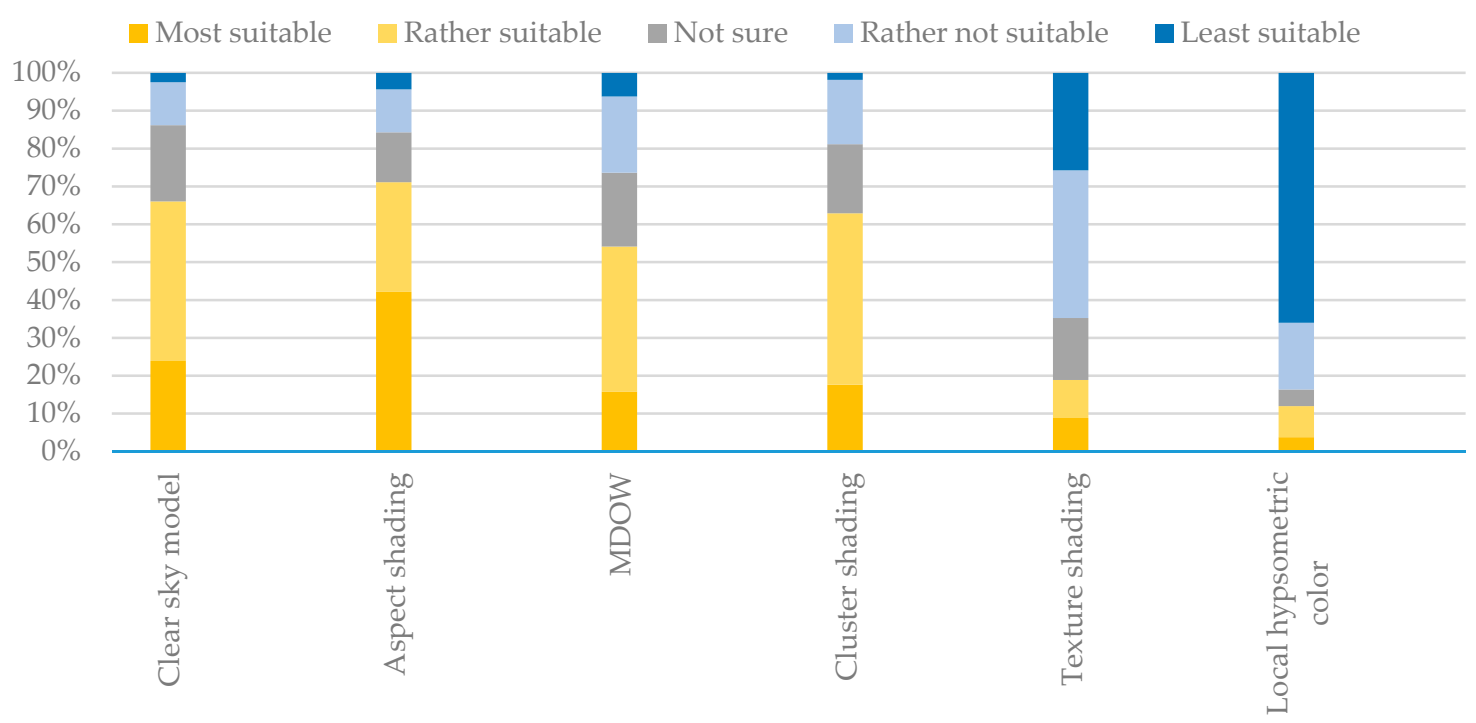

Figure 15. Survey results for glaciers.

The experts likewise chose mainly between the first four methods described above. The clear sky model depicts nicely both mountains and ice, aspect shading provides rich details on the glacier surface but at the same time gives an impression that mountain and glaciers are smoothed into each other. The MDOW is the method to go with for glacier detail, and cluster shading is here a compromise between the mountain and glacier detail. In the texture shading, mountain peaks look snowy and the glaciers look smooth, while the local hypsometric tints shading looks flat to the most respondents, even though it does show striations in the glacier. Several experts concluded that the ice texture does not have to stand out, but should look different to the rest of the terrain, and there is room for improvement with respect to larger relief forms to make them more visible.

\subsection{Results Summary}

To roughly evaluate the answers and to provide a better overview of the numbers with regard to each landform and method, the authors introduced an assessment index based on Equation (1):

$$
\mathrm{i}=\mathrm{N}_{\text {most suitable }}+\mathrm{N}_{\text {rather suitable }}-\mathrm{N}_{\text {not sure }}-\mathrm{N}_{\text {rather not suitable }}-\mathrm{N}_{\text {least suitable, }}
$$

The index values are converted into fractions and are presented in Table 2 (with the highest numbers highlighted). As can be seen from Equation (1), the positive index values show that a method is overall positively assessed by the participants and the negative values of the index reveal a bigger number of negative answers rather than positive. For most landforms, the highest index corresponds to the highest number of "most suitable" votes, except for folded mountains and V-shaped valleys, where the most suitable method was the clear sky model with vertical exaggeration.

A visual demonstration of relief shadings corresponding to the highest index values per landform is given in Figure 16. It shows the most suitable relief shading method applied to a selection of nine landforms, based on the answers of the 151 respondents worldwide. 
Table 2. Assessment indices per method and landform as fractions.

\begin{tabular}{|c|c|c|c|c|c|c|}
\hline $\begin{array}{ll}\text { Landforms } & \text { Methods } \\
\end{array}$ & $\begin{array}{c}\text { Clear Sky } \\
\text { Model }\end{array}$ & $\begin{array}{c}\text { Cluster } \\
\text { Shading }\end{array}$ & $\begin{array}{l}\text { Clear Sky Model with } \\
\text { Vertical Exaggeration }\end{array}$ & $\begin{array}{c}\text { Standard Hillshading with } \\
\text { NW Illumination }\end{array}$ & MDOW & Texture Shading \\
\hline Folded mountains & 0.55 & 0.21 & 0.12 & 0.17 & -0.48 & -0.56 \\
\hline Plateaus & 0.43 & 0.01 & -0.06 & 0.18 & -0.34 & -0.25 \\
\hline V-shaped valleys & 0.61 & 0.15 & 0.25 & -0.18 & -0.24 & 0.07 \\
\hline \multirow[t]{2}{*}{ Drumlins } & 0.29 & 0.48 & -0.36 & -0.55 & -0.67 & -0.64 \\
\hline & $\begin{array}{c}\text { Clear sky } \\
\text { model }\end{array}$ & $\begin{array}{l}\text { Cluster } \\
\text { shading }\end{array}$ & $\begin{array}{c}\text { Clear sky model with } S \\
\text { illumination and vertical } \\
\text { exaggeration }\end{array}$ & $\begin{array}{c}\text { Clear sky model with } \mathrm{S} \\
\text { illumination }\end{array}$ & MDOW & Texture shading \\
\hline U-shaped valleys & 0.32 & -0.64 & -0.04 & 0.47 & 0.12 & 0.02 \\
\hline Glaciers & 0.32 & 0.26 & 0.42 & -0.76 & 0.08 & -0.62 \\
\hline
\end{tabular}

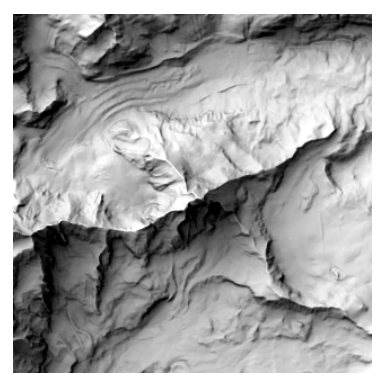

(a)

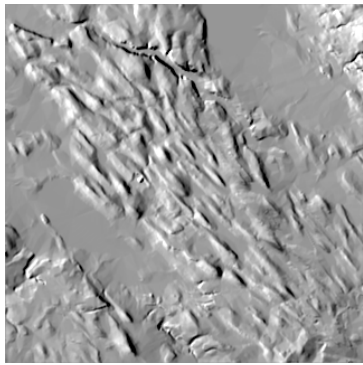

(d)

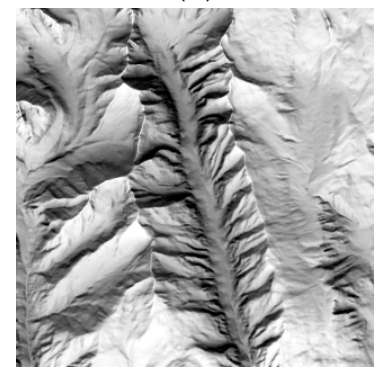

(g)

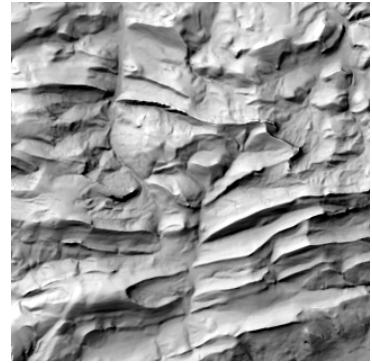

(b)

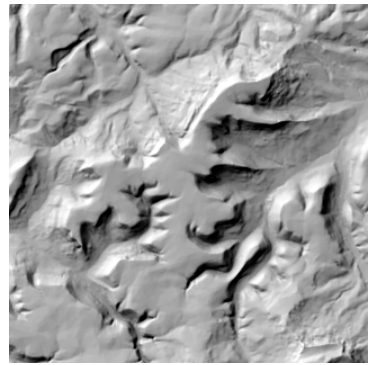

(e)

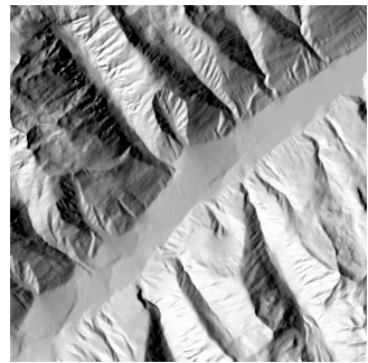

(h)

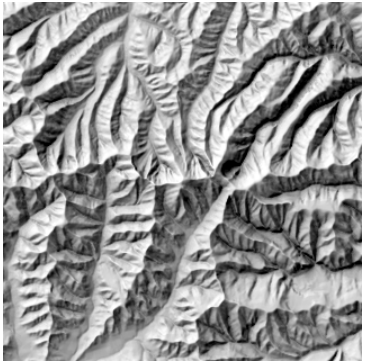

(c)

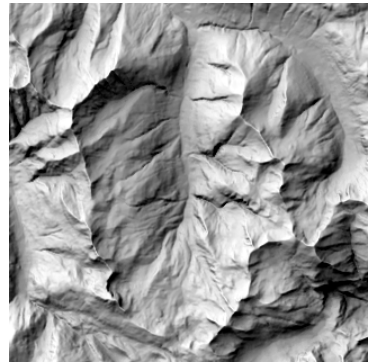

(f)

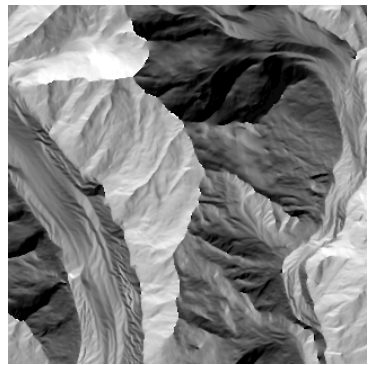

(i)

Figure 16. The most suitable relief shading methods per landform based on the survey results: the clear sky model method for (a) block mountains; (b) folded mountains; (c) mountains formed by erosion processes; (e) plateaus; and (f) V-shaped valleys; (d) the cluster shading for drumlins; (g) the clear sky model with custom (here S) illumination for U-shaped valleys; (h) the standard hillshading with custom (here W) illumination for alluvial fans; and (i) the aspect shading for glaciers. 


\section{Discussion}

One of the most common comments of the respondents regardless of a landform was about the purpose of a map that the relief shading is created for. Many of them mentioned that it is partly a matter of choice and depends on how dramatic the user wants the map to look. For instance, texture shading looked overall rather flat compared to the other examples, even though it is merged with the traditional hillshading, but combining it with additional thematic data overlaid on it would generally work well. It is a fair statement, and the authors did reason about it with the conclusion, that within this study "suitable" would mean the best visual appearance of relief shading itself, independent of its further use. Such questions would probably always arise because we know the application of relief shading is to a certain extent subjective and there is no totally right or wrong opinion.

The participants came across several issues when answering the questions. For instance, despite the respondents being asked to evaluate each landform independently of the rest of the terrain in each particular case, due to comments we could see that partially the participants commented on the look of the other landforms present in the images, or on their interplay. It was especially the case with alluvial fans, as they are subtle compared to the mountains around them. This interesting fact may suggest that it is not easy for map readers to abstract certain landforms from the rest of the setting, even if they are asked to, and that people tend to read the terrain as a whole and intuitively connect the relief forms between each other. This point is especially fair, since it is challenging to find a large-scale landscape composed of only one type of landform in the real world. This might also question the very purpose or practical applicability of this study. In the view of the authors, the study itself was conducted seeking to justify the approach of perceiving a landform as a separate terrain element of a full value, which can be a reliable base when referring to larger terrain elements such as landscape types. We dare to assume that if this endeavour did not meet all of our expectations, but also did not prove the opposite, and the further study addressing landscape types should be fulfilled.

For a few people it was challenging to match some of the aerial views to the relief shadings. It was indeed a predictable issue, but mainly with regard to non-cartographers due to the lack of their experience with handling geospatial data. In fact, it was done deliberately to actually empower the respondents to see an oblique aerial view of the landforms (the inclination angle had to be altered), and in some cases from a different angle to have a better overview of the landform elements (modified orientation angle).

It was confusing for a couple of participant to see several images at a time. The authors did consider showing successive shaded reliefs to let the participants focus on each of them, but the idea of parallel comparison of one image to another seemed eventually more advantageous. Moreover, having to browse through the six images multiple times to evaluate each of the methods would presumably take more time to complete the survey.

When evaluating the methods, the respondents were intentionally guided by manual relief shadings. This was done by the authors to achieve several goals: (1) to have a clear visual reference for everybody which are results we are striving to achieve, (2) to make more people aware of such an important technique, not as widespread to date as before, yet common and influential, and (3) to find out whether it is actually possible to emulate it automatically with regard to diverse landforms. The authors know, however, that there is no standardisation in hand drawing and among manual shading experts as it is present in analytical relief shading. Thus, the answers would depend to a certain extent on our choice of references (manually drawn reliefs), since the latter would certainly bias the respondents. Indeed, despite choosing excellent, high standard examples, for some landforms there were no unequivocal answers. In the case with drumlins, for instance, the respondents mainly chose between their oblong shape as highlighted in the manual example and the more rounded shape as seen on the aerial view image. For plateaus, the manual example likewise turned out to be confusing due to a more rounded top, although it could have happened because of the further printing purposes or an individual interpretation of a particular cartographer. However, the respondents made their 
choices based on the references provided and their own reflections, and we have got a trend in answers for further research, as a result.

In the current survey, each landform is represented by one specific sample area as a reference for the rest of the areas of the same kind. Though landforms vary in size, orientation and can be a part of different landscapes, which overall limits the results to the extents of the chosen areas. To ensure the ecological validity of the results for other territories containing the same landforms as in the survey, a follow-up study involving multiple sample areas for each of the landforms should be performed.

\section{Conclusions}

The survey was designed with the aim of identifying which analytical relief shading methods are efficient with regard to particular landforms. The authors primarily addressed the common lighting approaches such as using one light source with the improved NNW direction, applying several light sources, adjusting the light direction depending on the orientation of the slope, deploying the custom illumination direction to highlight certain terrain features, and illuminating terrain by means of the sky model with the 250 lighting directions.

The results of the survey confirm that the clear sky model can be generally applied to all the landforms of this survey, as it proved to provide the best looking relief shading due to a complex model emulating the sky illumination, incorporation of soft shadows, and an accent on larger relief forms. The results also correspond to our reflections and to the authors of the sky models method that they are mostly suitable for mountainous areas, and concerning the fact that applying vertical exaggeration brings more contrast and better accentuates larger relief form. We could see that also smaller forms like drumlins and glaciers, or those combining flat areas and slopes like plateaus can benefit from the sky model illumination. For alluvial fans, however, its illumination effect could be improved, in order to deliver more expressive relief shading. Cluster shading and the shading with NNW illumination provided overall rather similar results, although cluster shading was less successful at the depiction of plateaus, valleys, and alluvial fans, and the standard relief shading with NNW illumination worked as expected worse for linear landforms stretching parallel to the light direction. Our initial assumption was that texture shading would reveal more details on smaller landforms like glaciers or alluvial fans, but the output shadings did not look persuasive enough, probably because overlaid hillshading muffled the texture layer. A possible solution could be to apply the method at larger scales and to give more transparency to a hillshading layer, so that texture would stand out more. As tested before, the MDOW method provides better results in larger scales, for smaller landforms like alluvial fans or in the terrain where high level of detail needs to be preserved. Also, it has to be noted, that for some landforms, their orientation plays crucial role and defines the illumination direction, which is needed for relief shading with one point-source illumination. In those cases, we chose a custom illumination direction for drumlins and alluvial fans perpendicular to their stretching direction. In every particular case, it has to be adjusted individually. At the same time, the answers of the respondents led us to some new findings, such as that for glaciers most of their texture can be extracted by deriving aspect from the raster surface.

Important consideration in the context of this study is the visual aspect of terrain representation. It is determined by the ability of map users to imagine the spatial character of a particular landform, its shape, volume, orientation, and mutual relations of adjacent landforms. Yet again, it underlines the certain subjectivity of the study, as it addresses the visual perceptual of the terrain, which can hardly be expressed in measurable parameters.

Since only a limited selection of landforms, methods and their visualizations was tested, it is also necessary to state that the results are limited and conform to this survey setting. The results obtained within the study, may serve as a reference, but further research involving a broader range of methods, landforms, and more comprehensive analysis is needed.

The authors will consider the issues emerging in their further research. The next step will be the delineation of relief types, followed by the development of an algorithm that would apply the 
relief shading methods, which proved to deliver best results in relation to respective landforms, according to this survey. At the final stage, to increase the ecological validity of the research, we would complement the relief shading of an area with a heterogeneous terrain with other map elements and would demonstrate how our approach works within a map and not solely relief shading.

Supplementary Materials: The following are available online at http://www.mdpi.com/2220-9964/9/4/253/s1: Survey.pdf, SurveyResultsOverview.pdf, UserResponses.csv.

Author Contributions: Conceptualization, Marianna Farmakis-Serebryakova and Lorenz Hurni; data curation, Marianna Farmakis-Serebryakova; formal analysis, Marianna Farmakis-Serebryakova; investigation, Marianna Farmakis-Serebryakova; methodology, Marianna Farmakis-Serebryakova; resources, Marianna Farmakis-Serebryakova and Lorenz Hurni; supervision, Lorenz Hurni; visualization, Marianna Farmakis-Serebryakova; writing-original draft preparation, Marianna Farmakis-Serebryakova; writing-review and editing, Lorenz Hurni. All authors have read and agreed to the published version of the manuscript.

Funding: This research received no external funding.

Acknowledgments: The authors would like to thank Patrick Kennelly and Michael Wood for their valuable feedback, and the experts who left detailed comments when answering the survey questions. We appreciate the 151 people who took their time to complete the survey and those who helped to share the survey so that more people could complete it. The authors are also grateful to the three anonymous reviewers for their precious comments and suggestions.

Conflicts of Interest: The authors declare no conflict of interest.

\section{References}

1. Patterson, T. Shaded Relief. Available online: http://www.shadedrelief.com/ (accessed on 19 February 2020).

2. Jenny, B.; Räber, S. Relief Shading. Available online: http://www.reliefshading.com/ (accessed on 19 February 2020).

3. Zakšek, K.; Oštir, K.; Kokalj, Ž. Sky-view factor as a relief visualization technique. Remote Sens. 2011, 3, 398-415. [CrossRef]

4. Wiechel, H. Theorie und Darstellung der Beleuchtung von nicht gesetzmässig gebildeten Flächen mit Rücksicht auf die Bergzeichnung. Civilingenieur 1878, 24, 335-364.

5. Yoëli, P. Relief shading. Surv. Mapp. 1959, 19, 229-232.

6. Yoëli, P. Analytical hill shading. Surv. Mapp. 1965, 25, 573-579.

7. Yoëli, P. Analytical hill shading and density. Surv. Mapp. 1966, 26, 253-259.

8. Yoëli, P. The mechanisation of analytical hill shading. Cartogr. J. 1967, 4, 82-88. [CrossRef]

9. Yoëli, P. Die richtung des lichtes bei analytischer schattierung. Kartogr. Nachr. 1967, 17, 37-44.

10. Marsik, Z. Automatic relief shading. Photogrammetria 1971, 27, 57-70. [CrossRef]

11. Brassel, K. Modelle und Versuche zur Automatischen Schräglichtschattierung. Ph.D. Thesis, University of Zurich, Zurich, Switzerland, 1973.

12. Brassel, K. A model for automatic hill-shading. Am. Cartogr. 1974, 1, 15-27. [CrossRef]

13. Jenny, B.; Hurni, L. Swiss-style colour relief shading modulated by elevation and by exposure to illumination. Cartogr. J. 2006, 43, 198-207. [CrossRef]

14. Jenny, B. An interactive approach to analytical relief shading. Cartographica 2001, 38, 67-75. [CrossRef]

15. Yokoyama, R.; Shirasawa, M.; Pike, R.J. Visualizing topography by openness: A new application of image processing to digital elevation models. Photogramm. Eng. Remote Sens. 2002, 68, 257-265.

16. Kennelly, P.J.; Stewart, A.J. A uniform sky illumination model to enhance shading of terrain and urban areas. CaGIS 2006, 33, 21-36. [CrossRef]

17. Kennelly, P.J.; Stewart, A.J. General sky models for illuminating terrains. Int. J. Geogr. Inf. Sci. 2014, 28, 383-406. [CrossRef]

18. Podobnikar, T. Multidirectional visibility index for analytical shading enhancement. Cartogr. J. 2012, 49, 195-207. [CrossRef]

19. Kennelly, P.J. Terrain maps displaying hill-shading with curvature. Geomorphology 2008, 102, 567-577. [CrossRef] 
20. Willett, W.; Jenny, B.; Isenberg, T.; Dragicevic, P. Lightweight relief shearing for enhanced terrain perception on interactive maps. In Proceedings of the Conference on Human Factors in Computing Systems (CHI), Seoul, Korea, 18-23 April 2015; pp. 3563-3572.

21. Buddeberg, J.; Jenny, B.; Willett, W. Interactive shearing for terrain visualization: An expert study. GeoInformatica 2017, 21, 643-665. [CrossRef]

22. Marston, B.E.; Jenny, B. Improving the representation of major landforms in analytical relief shading. Int. J. Geogr. Inf. Sci. 2015, 29, 1144-1165. [CrossRef]

23. Mark, R.K. A Multidirectional, Oblique-Weighted, Shaded-Relief Image of the Island of Hawaii; Open-File Report 92-422; U.S. Geological Survey: Reston, VA, USA, 1992. [CrossRef]

24. Terrain Tools Sample v1.1. Available online: https://www.arcgis.com/home/item.html?id= 4b2ea7c5f87d476a8849c804b81667aa (accessed on 4 July 2019).

25. Veronesi, F.; Hurni, L. Changing the light azimuth in shaded relief representation by clustering aspect. Cartogr. J. 2014, 51, 291-300. [CrossRef]

26. Veronesi, F.; Hurni, L. A GIS tool to increase the visual quality of relief shading by automatically changing the light direction. Comput. Geosci. UK 2015, 74, 121-127. [CrossRef]

27. Imhof, E. Cartographic Relief Presentation; Walter de Gruyter \& Co.: Berlin, Germany, 1982.

28. Federal Office of Topography Swisstopo. Available online: https://www.swisstopo.admin.ch/ (accessed on 20 February 2020).

29. DHM25. Available online: https://shop.swisstopo.admin.ch/en/products/height_models/dhm25 (accessed on 20 February 2020).

30. Imhof, E. Cartographic Relief Presentation; ESRI Press: Redlands, CA, USA, 2007.

31. Biland, J.; Çöltekin, A. An empirical assessment of the impact of the light direction on the relief inversion effect in shaded relief maps: NNW is better than NW. CaGIS 2017, 44, 358-372. [CrossRef]

32. Fold (Geology). Available online: https://en.wikipedia.org/wiki/Fold_(geology) (accessed on 18 December 2019).

33. Erosion. Available online: https://en.wikipedia.org/wiki/Erosion (accessed on 18 December 2019).

34. Kennelly, P.; Stewart, A.J. Relief shading with sky models. In Wiener Schriften zur Geographie und Kartographie; Kriz, K., Ed.; Institut für Geographie und Regionalforschung der Universität Wein Kartographie und Geoinformation: Vienna, Austria, 2015; Volume 21, pp. 69-76.

35. Brown, L. Texture shading: A new technique for depicting terrain relief. In Proceedings of the 9th ICA Mountain Cartography Workshop, Banff, AB, Canada, 22-26 April 2014.

36. Huffman, D.P.; Patterson, T. The design of gray earth: A monochrome terrain dataset of the world. Cartogr. Perspect. 2013, 74, 61-70. [CrossRef] 